\title{
An Experimental Study on the Pathway of Iron Transfer from Macrophages to Erythrocytes in Rat Liver
}

\author{
Toshiro Ono $^{1 *}$, Masahiko Akita ${ }^{1}$, Tadashi Tsujii ${ }^{2}$ and Satimaru Seno ${ }^{1}$ \\ ${ }^{1}$ Division of Pathology and ${ }^{2}$ Ultrastructure Research, Shigei Medical Research \\ Institute, 2117 Yamada, Okayama 701-02, Japan
}

\begin{abstract}
In order to reveal the pathway of iron release from macrophages, a ${ }^{59} \mathrm{Fe}$-labelled ferric hydroxide-potassium polyvinyl sulfate complex (Fe-PVS) was injected intravenously into anemic rats and the level of radioactivity in the liver, spleen, bone marrow, blood plasma and red blood cells ( $R B C)$ was estimated at various time intervals after the injection. Histochemical observation of ferric iron and ferritin in the liver was also made on anemic rats treated using unlabelled Fe-PVS. Fe-PVS injection promoted the recovery of anemia causing a rapid increase in the RBC number, with activated erythropoiesis occurring in the spleen and bone marrow. Soon after the injection, most of the radio iron was found in the liver with a small amount in the circulating erythrocytes, bone marrow and spleen. The iron level in the liver decreased gradually with a rapid increase in the iron level of the erythrocytes which reached a very high level 6 days after the ${ }^{59} \mathrm{Fe}-\mathrm{PVS}$ injection. Histochemical observations showed a heavy deposition of ferritin in the Kupffer cells 3 days after Fe-PVS injection. This deposition was minimized after 6 days with an increase in the level of ferritin in the parenchymal cells in the central area of acini. The level of radioferritin estimated biochemically in the nonparenchymal cell fractions of the liver revealed that the level dropped by about one third approximately 3.5 days after the Fe-PVS injection, showing the stimulated ferritin release at this stage. Results indicate that Kupffer cells in the liver play an important role in ferritin synthesis from the phagocytized iron compounds and that the iron is supplied for erythroid cell proliferation.
\end{abstract}

It is generally believed that the senesent red blood cells are phagocytized by macrophages of the reticuloendothelial system, hemoglobin is decomposed, and the released iron is sent to the bone marrow erythropoietic focuses by serum apotransferrin to be reutilized for the new hemoglobin synthesis in differentiating erythroblasts (6). Further, the excess iron is stored as ferritin or hemoglobin in the macrophages and other cells $(11,26)$. However, the detailed pathway of the iron release from macrophages and its transfer to the transferrin to be transported to the erythropoietic focuses have remained unclear. Recently, though, the role of ferritin in the iron release from macrophages has been updated. Some experiments show that a certain amount of ferritin is released from the macrophages after phagocytosis of the erythrocytes or iron compounds $(4,8,24)$.

* Present address: Department of Oral Pathology, Okayama University Dental School, 2-5-1 Shikatacho, Okayama 700, Japan 
In the experimental studies on iron metabolism and ferritin synthesis, an iron dextran complex has been widely used. The dextran iron injected into a vein or subcutaneous tissue is taken up by macrophages of the so-called reticuloendothelial system. Within these cells, the dextran iron is decomposed so that the iron can be used for ferritin synthesis. Dextran iron is a very stable compound and requires a few weeks to be decomposed for ferritin synthesis in the cells; it elicits a weak Prussian blue reaction in the test (18).

As reported previously, anionic Fe-PVS particles injected intravenously were phagocytized solely by macrophages of the reticuloendothelial system $(21,22)$, and ferritin was synthesized within a few days (20). Thus, Fe-PVS is a useful tool for the study of ferritin synthesis in macrophages and the subsequent iron release. Observations have revealed that most of the iron of the intravenously injected FePVS was initially found in the Kupffer cells of the liver, but they were transferred rapidly to the red blood cells whose ${ }^{59} \mathrm{Fe}$ radioactivity reached a very high level 2 days after the injection. The serum iron level was always very low throughout the experiment. Although the bone marrow and spleen indicated stimulated erythropoiesis, they were also very slow in the uptake of radioiron. Immunohistochemical studies revealed that Kupffer cells synthesized ferritin effectively with the ingested Fe-PVS particles and then released it into the sinusoids and Disse's spaces. Ferritin eventually appeared in the parenchymal cells within the central area of acini. The data suggests that the Kupffer cells play an important role in ferritin synthesis and iron transfer for erythrocyte maturation.

\section{MATERIALS AND METHODS}

A hundred and two male albino rats of Wistar strain, weighing $250-300 \mathrm{~g}$ were used in this study. The animals were divided into five groups: group I contained 21 rats, group II, 6 rats, group III, 36 rats, group IV, 36 rats, and group V, 3 rats.

An anemic condition was induced in the animals of group I by drawing blood from the jugular vein. Three $\mathrm{ml}$ of blood was extracted from each animal for 3 consecutive days so that each sample totalled $8-9 \mathrm{ml}$. On the foruth day, $3 \mathrm{ml}$ of ${ }^{59} \mathrm{Fe}$-labelled Fe-PVS $(0.45 \mu \mathrm{Ci} / \mathrm{ml})$ was injected intravenously into each animal. The animals were sacrificed in groups of 3 by bleeding them to death at $6 \mathrm{~h}, 1,2,3,3.5,4$ and 6 days after the injection. The liver, spleen and one femor were then removed and the level of radioactivity in each of these organs along with that of the RBC and blood plasma was counted by a sintillation counter. The radioactivity was expressed as a percent of the injected dose.

Six animals in group II were treated just as those in group I. Anemic conditions were induced in the rats of group II in the same way as described above. In this group, the animals were sacrificed in two groups of three after 3 and 4 days, respectively. After sacrifice, the liver of each animal was perfused with $10 \mathrm{mM}$ of HEPES solution containing $\mathrm{Ca}^{2+}$ and $0.05 \%$ collagenase through the portal vein (16). After perfusion, the livers were gently crushed. The parenchymal cells were precipitated by centrifugation of the cell suspension at $50 \times \mathrm{g}$, and the nonparenchymal cells were obtained as the precipitate by centrifuging the remaining supernatant at $500 \times \mathrm{g}(7)$. To observe the incorporation of ${ }^{59} \mathrm{Fe}$ into ferritin, the cells in each fraction were homogenized and the ferritin was isolated from the homogenates by the specific immunoprecipitation method. The homogenate was centrifuged at $200 \times \mathrm{g}$ for $30 \mathrm{~min}$. The resulting supernatant was heated at $75^{\circ} \mathrm{C}$ for $30 \mathrm{~min}$ with gentle shaking, and then centrifuged at $2000 \times \mathrm{g}$ for $30 \mathrm{~min}$ to remove the heat-denatured proteins. The supernatant was mixed with Sepharose 4B covalently bound to a specific antibody against rat liver ferritin (20) and 
suspended in $0.1 \mathrm{M}$ PBS, pH 8.0. The mixture was incubated at $37^{\circ} \mathrm{C}$ for $30 \mathrm{~min}$. After incubation, the mixture was cooled and maintained overnight at $4^{\circ} \mathrm{C}$. The precipitate was collected by centrifugation at $3000 \times \mathrm{g}$ for $10 \mathrm{~min}$ and washed 4 times with PBS. Radioactivity in the precipitate was counted by a sintillation counter.

An anemic condition was induced in the animals in group III in the same way as those in group I. Each animal then received $3 \mathrm{ml}$ of unlabelled Fe-PVS by injection. The number of RBCs and reticulocytes in the circulating blood was counted daily. The serum iron level was also measured with a ESA Autoanalyzer. The animals were sacrificed by decapitation in groups of 3 at $1.5 \mathrm{~h}, 1,2,3,3 \frac{1}{6}, 3 \frac{1}{3}, 3 \frac{1}{2}, 3^{2} / 3,3^{5} / 6,4$ and 6 days after the injection. Animals of group IV served as anemic controls and were injected with a physiological saline solution instead of Fe-PVS. Those in group V served as healthy controls and were sacrificed without having received any additional treatment. After sacrifice, the liver, spleen and femoral bone marrow of these animals were removed, fixed in Zamboni's fixative for $24 \mathrm{~h}$
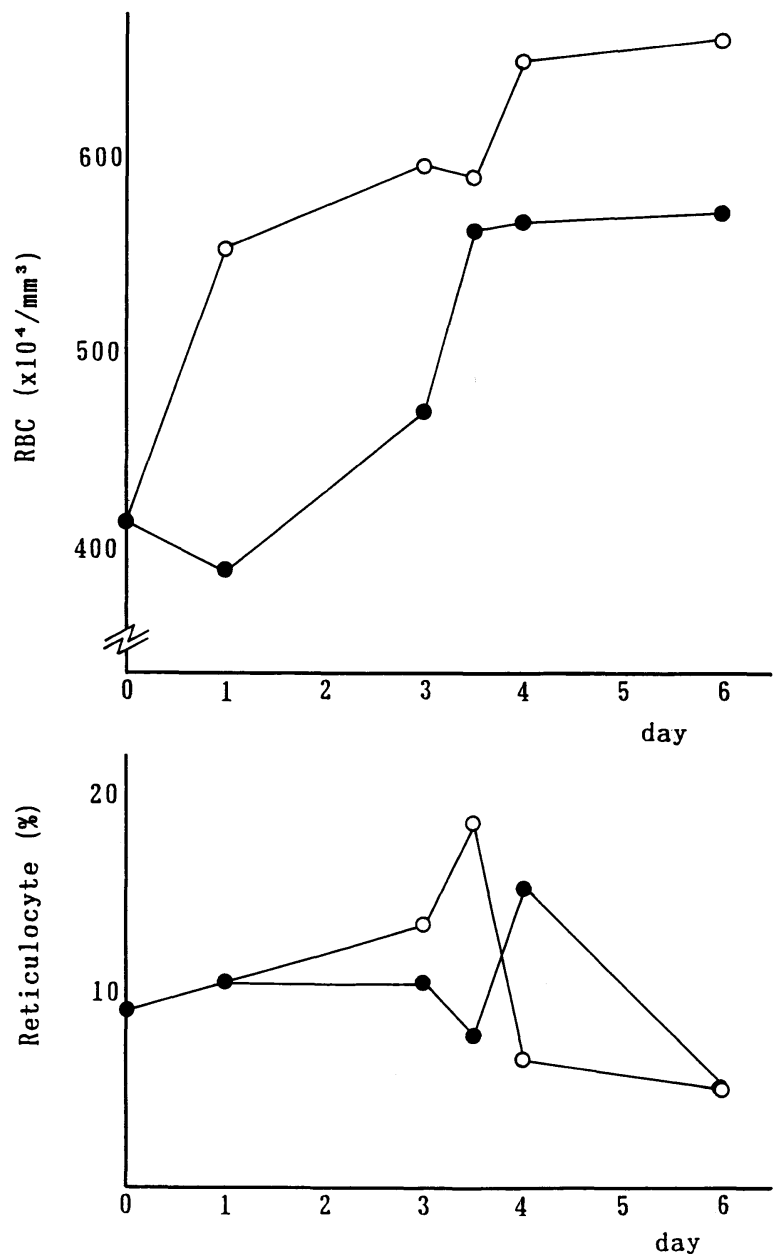

Fig. 1. Reticulocyte count and RBC number in circulating blood of anemic and Fe-PVS injected rats at various time intervals. $\bullet$, anemic control rats; $\bigcirc$, Fe-PVS injected rats. Results are the means of triplicate measurements. 


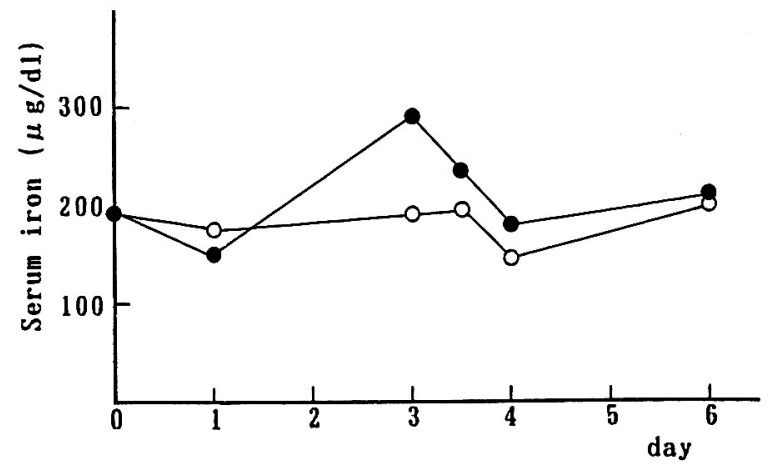

Fig. 2. Iron concentration in serum of anemic and Fe-PVS injected rats at various time intervals. $\bullet$, anemic control rats; $\mathrm{O}$, Fe-PVS injected rats. Results are the means of triplicate measurements.

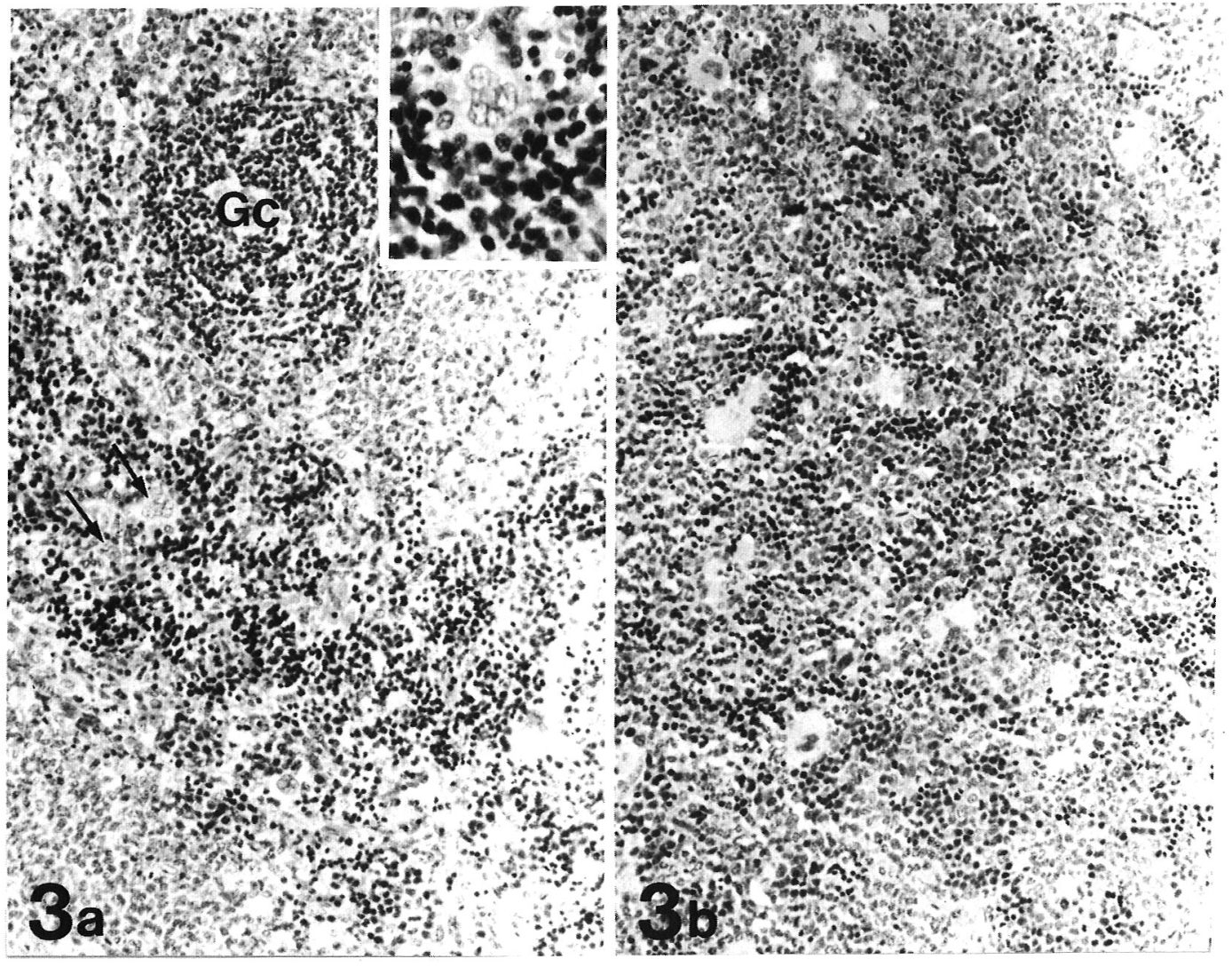

Fig. 3. Light micrographs of (a) spleen and (b) bone marrow tissues taken $3.5 \mathrm{~d}$ after intravenous injection of Fe-PVS. Note numerous erythroblastic clusters in the red pulp of spleen and bone marrow. Some megakaryocytes are also found in the spleen (arrows). Inset in (a) shows a higher magnification of erythroblastic clusters. Gc, Germinal center. Hematoxylin-eosin staining. $a$ and $b, \times 150$; inset, $\times 300$. 
(30), dehydrated, and embedded in paraffin. Four serial sections were obained from each sample, two for hematoxylin-eosin and Prussian blue staining, and two for the ferritin staining by the immunoperoxidase method (PAP) (29). Prior to applying the PAP method, the endogeneous peroxidase production was blocked by treating the sections with $0.3 \% \mathrm{H}_{2} \mathrm{O}_{2}$ in a methanol solution. In the PAP method, rabbit IgG against rat liver ferritin obtained in this laboratory (20) was used. Swine IgG against rabbit IgG (Dako, Denmark) was used as the second anitbody. All the PAP staining procedures were carried out using Dako's kit. For the control subjects the tissue sections were treated with normal rabbit serum in place of the rabbit anti-ferritin antibody.

The liver tissue was also fixed in $2 \%$ glutaraldehyde and processed for electron microscopy. Sections of silver color were cut with a Reichert OmU-3 ultramicrotome and observed under a Hitachi electron microscope, H-700, with or without staining by uranyl acetate and lead citrate.

\section{RESULTS}

In the healthy rats the RBC count was about $8,800,000 / \mathrm{mm}^{3}$ and decreased to about $4,150,000 / \mathrm{mm}^{3}$ by blood withdrawal of $8-9 \mathrm{ml}$ daily over 3 days. However there was a marked increase in the reticulocyte count. After the final blood withdrawal the animals gradually recovered from the anemic condition. Their RBC number, however, showed a lower level even 4 and 6 days after the blood extraction. Fe-PVS injection promoted the recovery of anemia, inducing a rapid increase in the RBC count (Fig. 1). A steady increase in the number of circulating reticulocytes was observed and reached a maximum at 3.5 days. Thereafter, it showed a progressive decrease reaching $5 \%$, the normal level, by day 6 (Fig. 1). The serum iron level was not elevated by Fe-PVS injection. An insignificant amount of

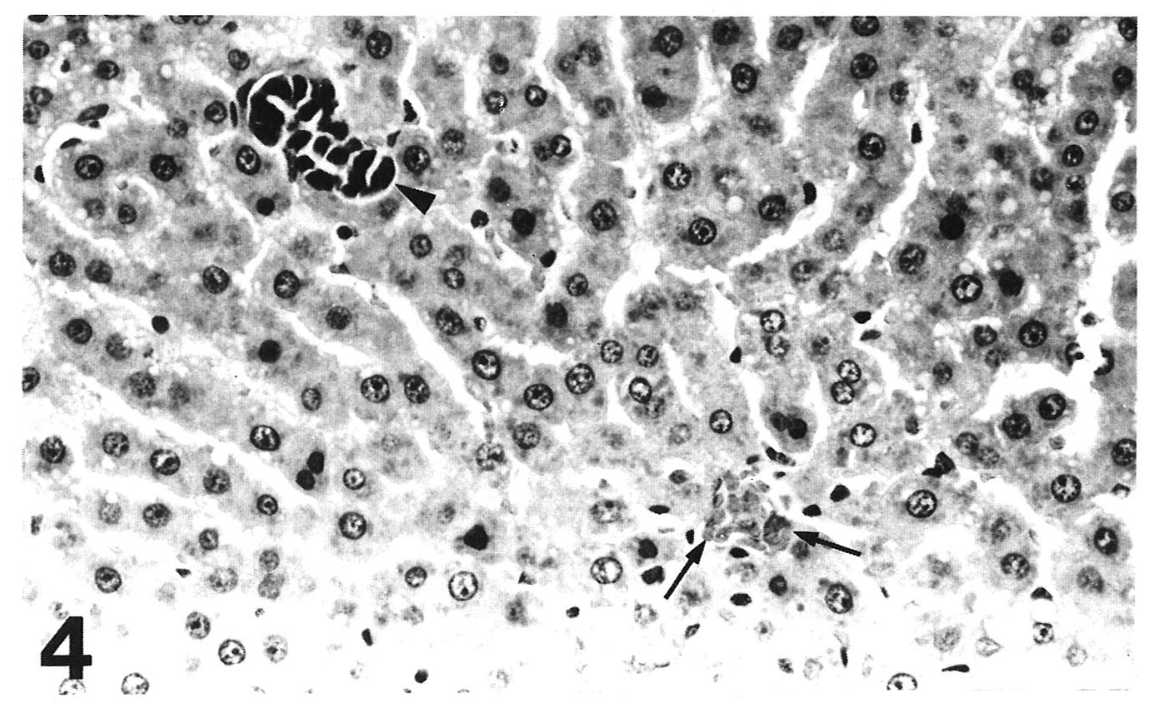

Fig. 4. Light micrograph of liver tissue taken 3.5 d after intravenous injection of Fe-PVS. Many red cells within sinusoids (arrows). A small erythroblastic clusters also are found in perisinusoidal space (arrow head). Hematoxylin-eosin staining. $\times 300$. 

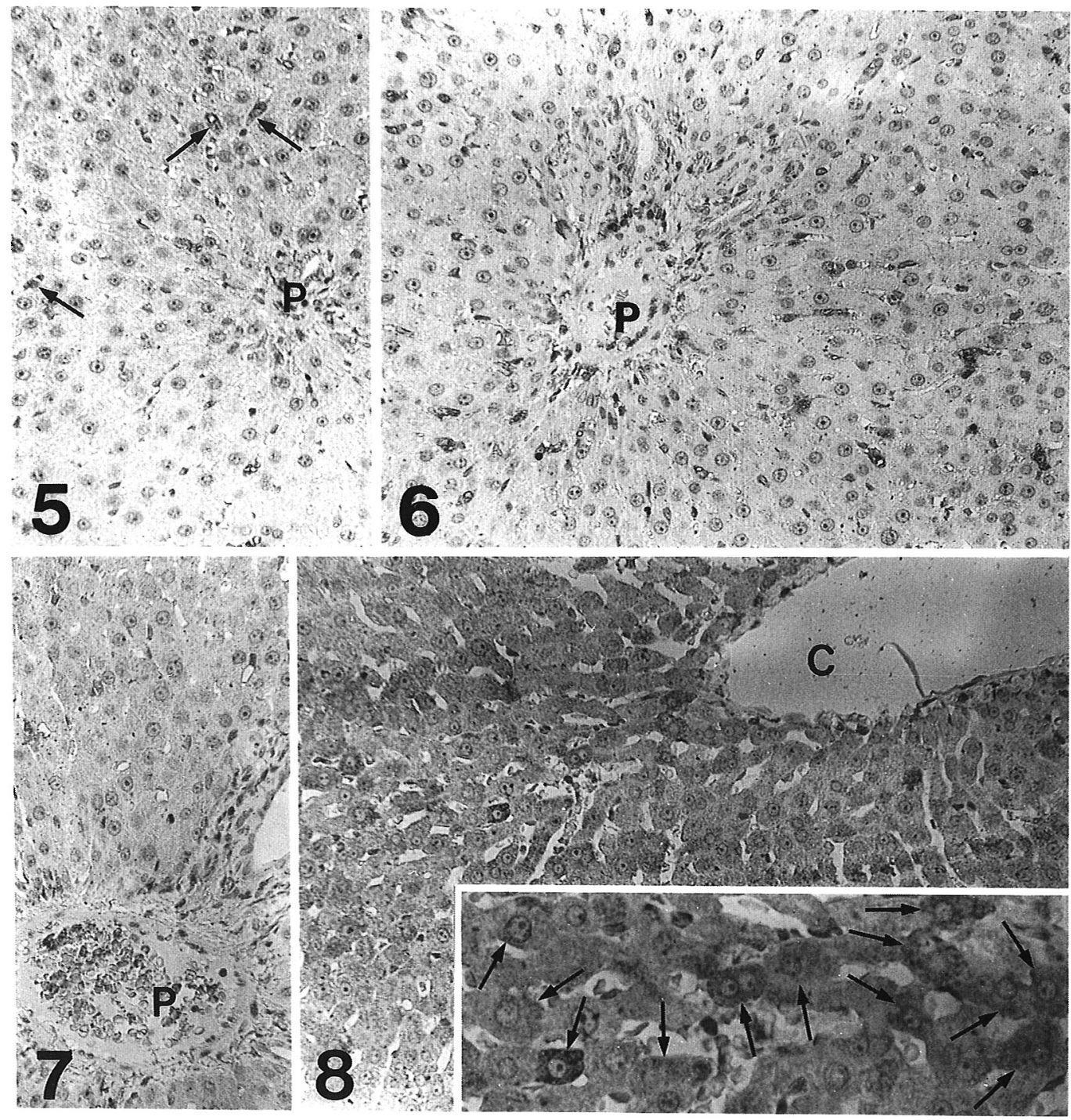

Fig. 5 to 9 show immunohistochemical staining of ferritin in liver tissues at varied time after intravenous injection of Fe-PVS. PAP method.

Fig. 5. Five hours after the injection: some Kupffer cells show intracytoplasmic staining (arrows). P, Portal vein. $\times 190$.

Fig. 6. Three days after the injection: note the increased number of highly ferritin-positive Kupffer cells. A small amount of ferritin is detected in the parenchymal cells. $\times 190$.

Fig. 7. Four days after the injection: ferritin is not detected in Kupffer cells even around the portal vein $(\mathrm{P}) . \quad \times 190$.

Fig. 8. Four days after the injection: most of the parenchymal cells around the central area of the lobules show a high degree intracytoplasmic ferritin staining. Inset shows a higher magnification of the cells stained in granules in the cytoplasm (arrows). C, Central vein. $\times 190$; inset, $\times 380$. 
difference was observed in the anemic animals treated with Fe-PVS injection and those without (Fig. 2). Histologic observations revealed a stimulated erythropoiesis in the spleen and bone marrow of all the anemic animals treated with or without $\mathrm{Fe}$ PVS injection. A number of large-sized erythroblastic foci were found in the bone marrow and red pulp of the spleen (Fig. 3). Observations of liver tissues of the anemic animals revealed a few small erythropoietic focus in the perisinusoidal spaces, and many red cell stagnations within the sinusoids (Fig. 4). The liver tissue sections from the anemic animals which received Fe-PVS injection gave a distinct Prussian blue reaction in the Kupffer cells. The Kupffer cells showed blue granules in the cytoplasm as early as $5 \mathrm{~h}$ after the Fe-PVS injection, while the parenchymal cells and endothelial cells showed a negative stain in the reaction. The number of Prussian blue positive Kupffer cells increased for up to 2 days, and then decreased gradually. The tissue taken from the animals in groups III and IV showed negative staining in the Prussian blue reaction.

By immunohistochemical staining of ferritin samples from healthy controls exhibited a weak reaction for ferritin in some centrolobular parenchymal cells, indicating zonal distribution of stored ferritin, as previously reported (15). In contrast, in the group IV animals, ferritin was not detected in the Kupffer cells nor in the parenchymal cells. In the group III animals, ferritin appeared in some Kupffer cells $5 \mathrm{~h}$ after the injection, although the reaction was rather weak (Fig. 5). However, the number of ferritin-positive Kupffer cells increased gradually with an increase in the reaction intensity. Three days after Fe-PVS injection, most of the Kupffer cells lying in the periphery of the lobules were heavily laden with ferritin
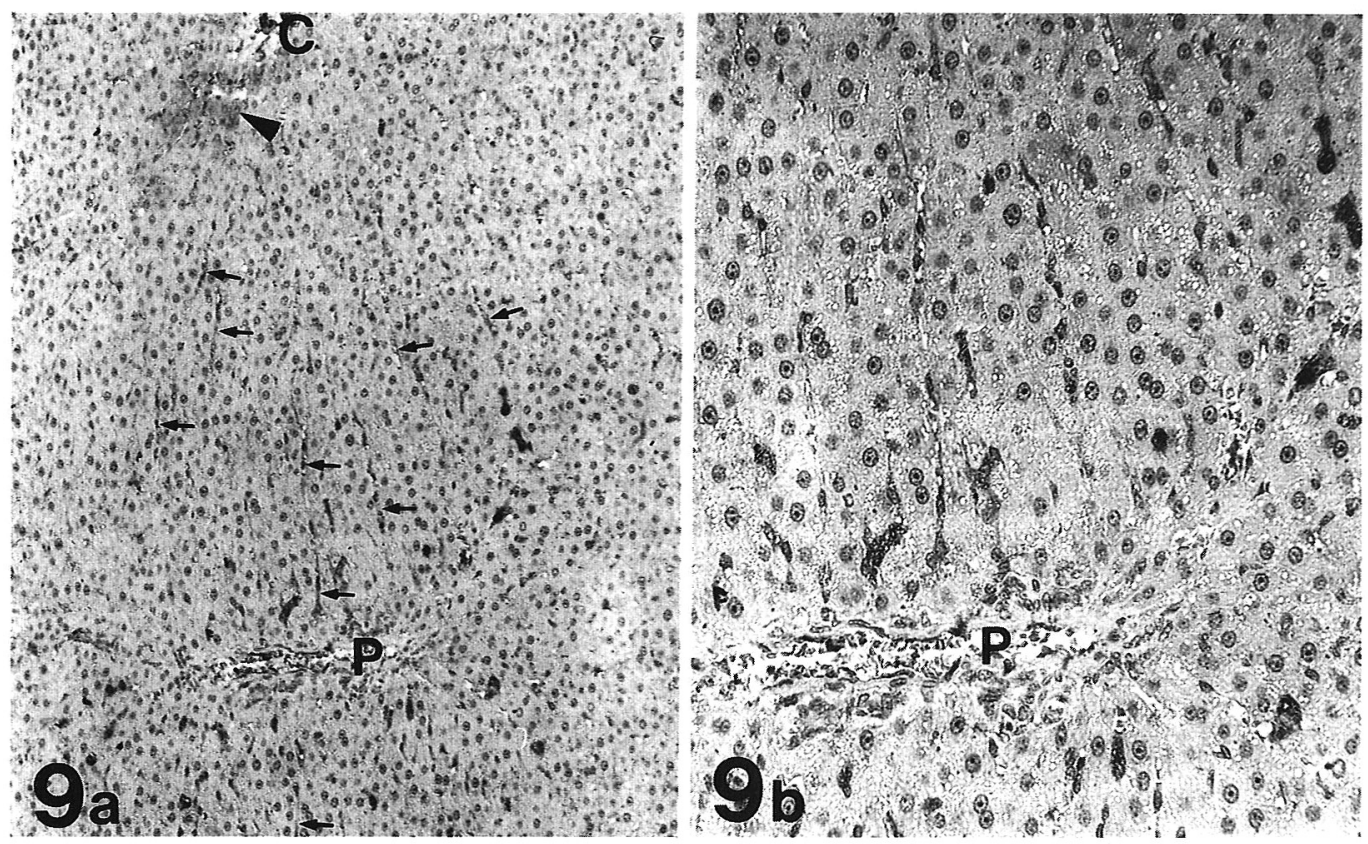

Fig. 9. Seventy six hours after the injection: a) note that ferritin is detected along sinusoid (arrows) and in the Kupffer cells. Some parenchymal cells in the central area of lobules became weakly ferritin positive (arrow head). b) Higher magnification of (a). $a, \times 95 ; b, 190$. 


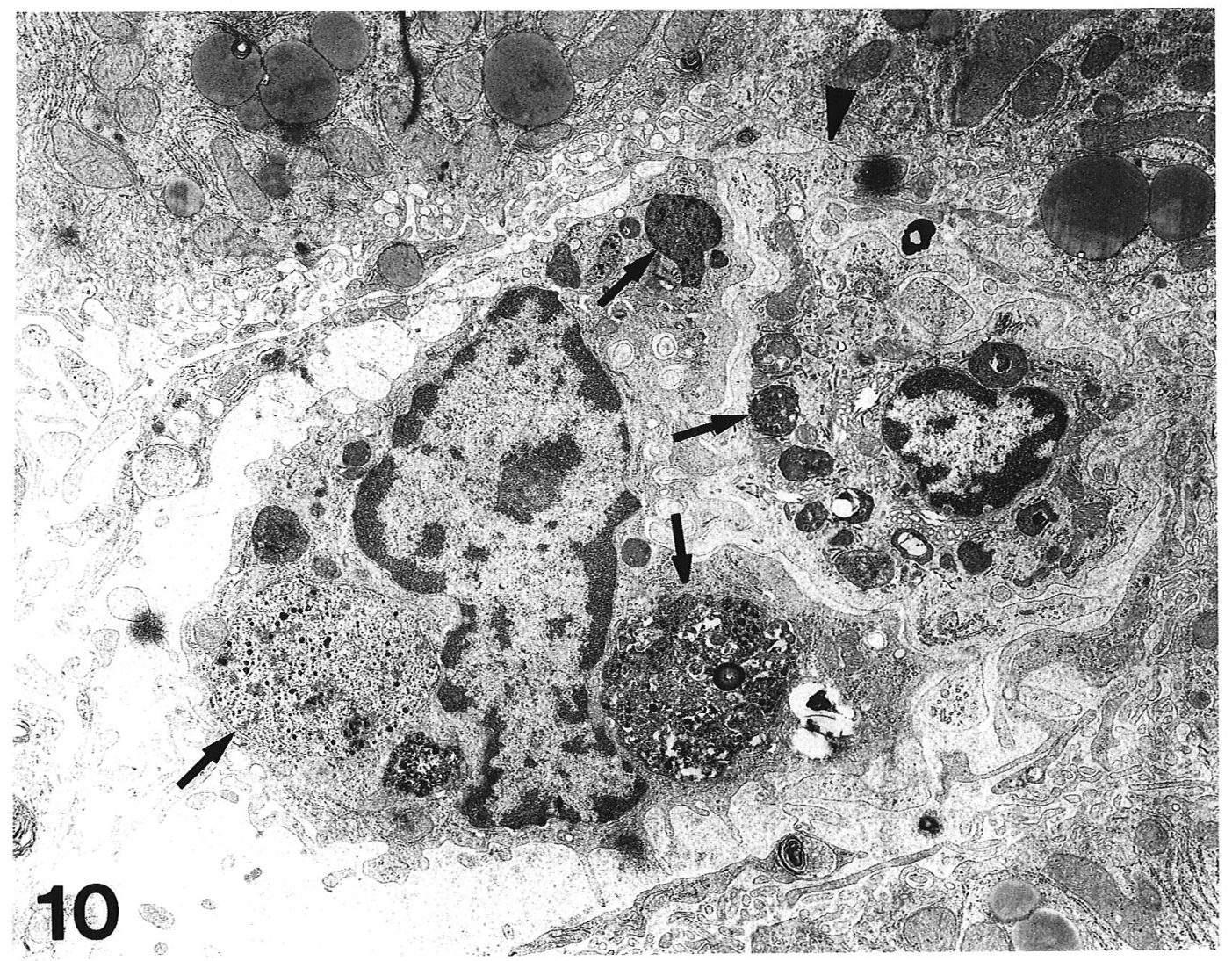

Fig. 10. Electron micrograph of a section of liver taken $2 \mathrm{~d}$ after the injection of Fe-PVS. Fe-PVS particles are found in the phagolysosomes of Kupffer cells (arrows). Kupffer cell extend the process in the Disse's space (arrow head). The tissue was stained with uranyl acetate and lead citrate. $\times 9,000$.

and showed marked edema (Fig. 6). At this stage most of the parenchymal cells indicated no detectable reaction to the ferritin. Four days after the Fe-PVS injection, however, a distinct positive reaction to ferritin appeared in the centrolobular parenchymal cells with a marked decrease in the reaction intensity of ferritin shown in the Kupffer cells. Some of the parenchymal cells exhibited a large number of ferritinpositive granules in the cytoplasm (Figs. 7 and 8). The ferritin content in the parenchymal cells was much higher than that of the healthy controls. These findings in-

Fig. 11. Electron micrograph of a section of liver taken $3.5 \mathrm{~d}$ after the injection of Fe-PVS. Note that reticulocytes (R) show intimate contact with an adjacent Kupffer cell (K) within the sinusoid. Inset shows a micropinocytic vesicle found the in reticulocyte. Tissue was stained with uranyl acetate and lead citrate. $\times 7,600$; inset, $\times 21,600$.

Fig. 12. Electron micrograph of a part of the cytoplasm of a Kupffer cell and sinusoidal wall taken $3 \mathrm{~d}$ after the injection of Fe-PVS. Note that numerous electron-dense ferritin particles are scattered throughout the cytoplasmic matrix of the Kuppfer cell (K). Some ferritin particles are also present in the perisinusoidal or Disse's space (arrows). E, Endothelial cell; P, Parenchymal cell. Unstained section. $\times 36,000$. 

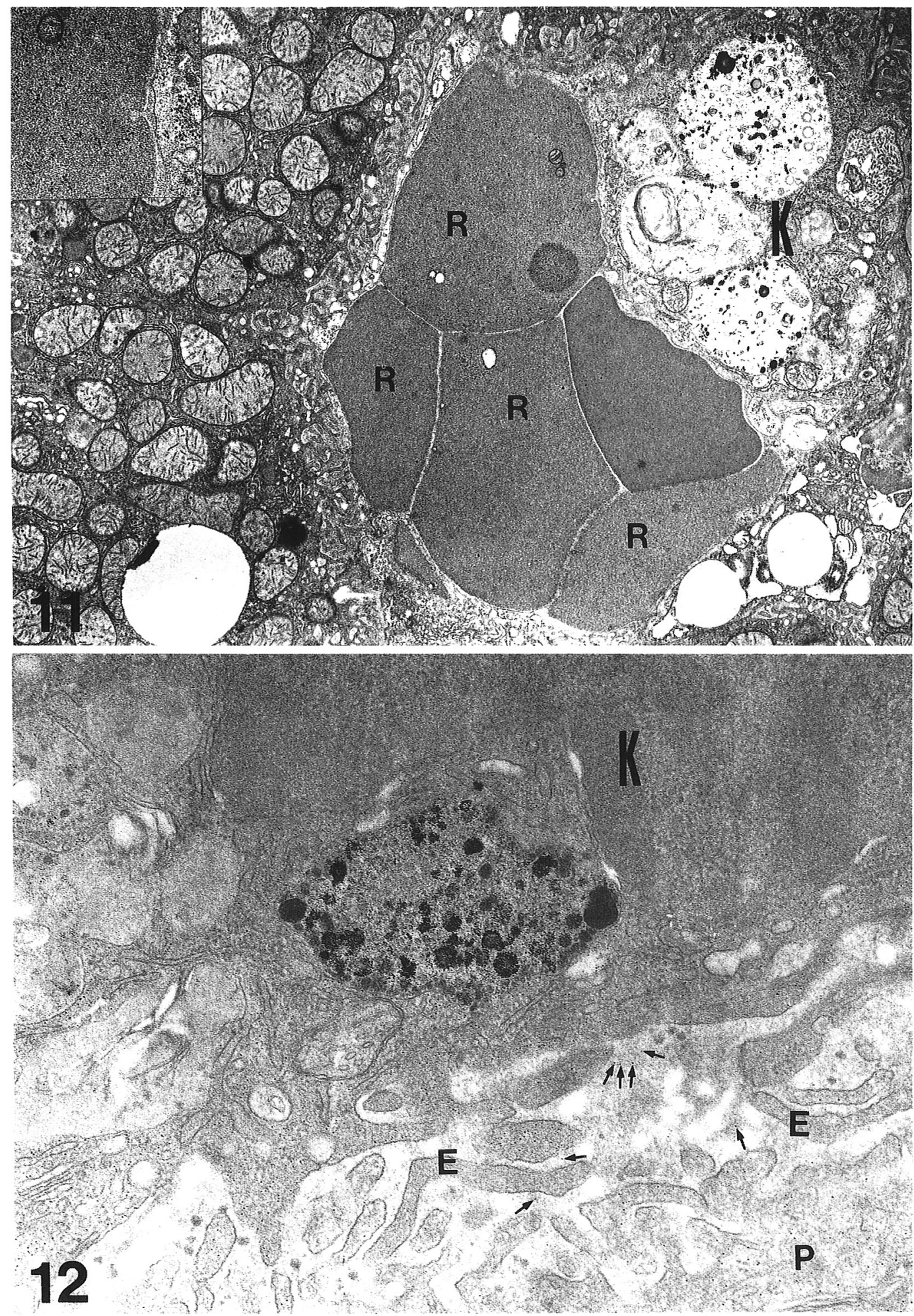
dicated that a rapid transfer for ferritin from the Kupffer cells to the parenchymal cells occurred between 3 and 4 days after the Fe-PVS injection. In the liver tissues taken $76 \mathrm{~h}$ after Fe-PVS injection, a linear positive reaction to ferritin was detected along the sinusoids and Disse's spaces (Fig. 9).

Electron microscope observation of thin sections of the liver taken 2 days after the Fe-PVS injection revealed electron-opaque colloid particles only in the phagolysosomes of the Kupffer cells (Fig. 10). Reticulocytes were occasionally observed to be in contact with the Kupffer cell within the sinusoid, i.e., in contact with the adjacent Kupffer cell (Fig. 11). Detailed information on the distribution of ferritin was obtained by observing unstained sections. A large number of ferritin particles was scattered throughout the cytoplasmic matrix of the Kupffer cells 3 days after the injection, with some particles found in the sinusoid and Disse's spaces (Fig. 12). This suggests that the ferritin particles were released from Kupffer cells into the surrounding spaces.

In the animals receiving i.v. injection of ${ }^{59} \mathrm{Fe}-\mathrm{PVS}$ after blood extraction, nearly $60 \%$ of the injected iron was found in the liver 6 to $24 \mathrm{~h}$ after injection. Thereafter, the radioactivity of the liver decreased gradually to $20 \%$ by day 6 after injection with a steady increase occurring in the $\mathrm{RBC}$ radioactivity. This increase was from $33 \%$ to $75 \%$ (Fig. 13). The radioactivity of the spleen was much lower than that of the liver and RBCs. Only $6.5 \%$ of the injected dose was found in the spleen 1 day

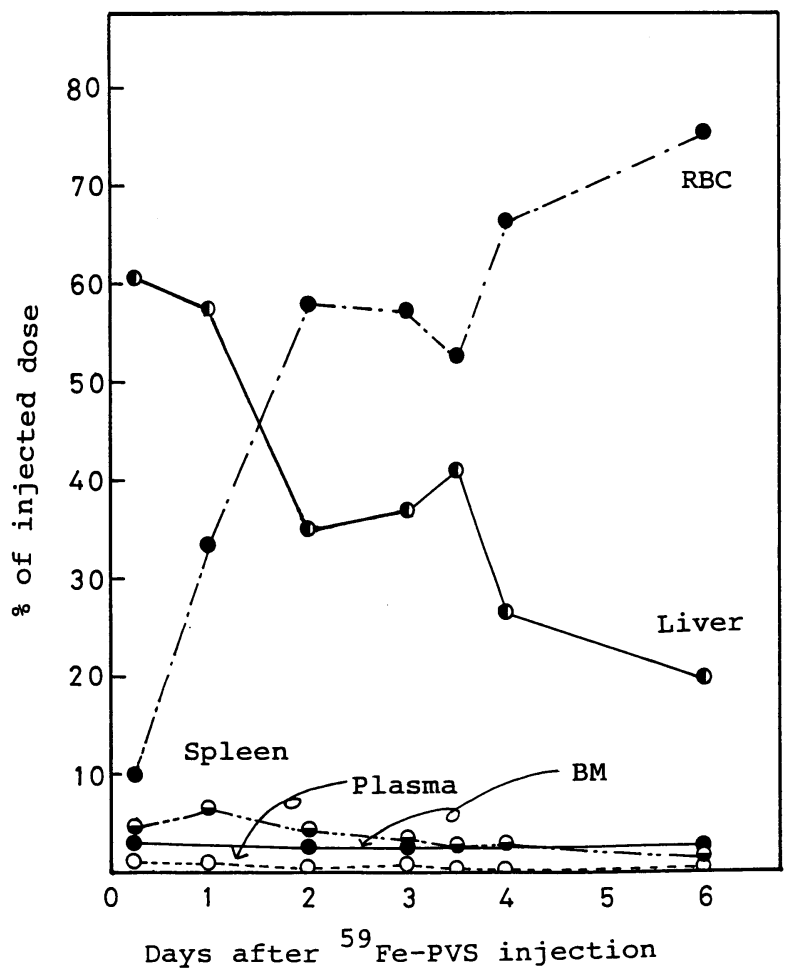

Fig. 13. Uptake of radioiron in the liver, $\mathrm{RBC}$, spleen, blood plasma and bone marrow (BM) at various time periods after intravenous injection of ${ }^{59} \mathrm{Fe}-\mathrm{PVS}$, and expressed as a percent of the injected dose. Results are the means of triplicate measurements. 


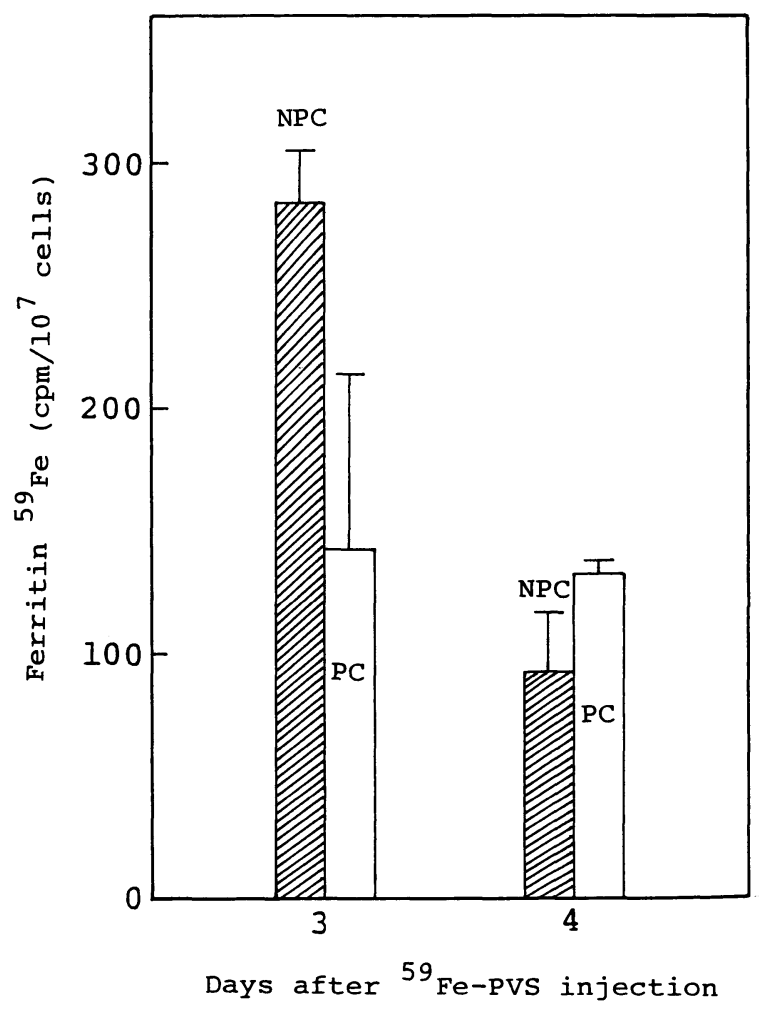

Fig. 14. Localization of ${ }^{59} \mathrm{Fe}$-ferritin in the parenchymal (PC) and nonparenchymal cells (NPC) at 3 and 4 days after intravenous injection of ${ }^{59} \mathrm{Fe}-\mathrm{PVS}$. PC and NPC were separated by collagenase perfusion and differential centrifugation. Ferritin in PC and NPC was determined as ${ }^{59} \mathrm{Fe}$ activity by the specific immunoprecipitation method. Results are the means of triplicate measurements $( \pm \mathrm{SD})$.

after injection; this then decreased gradually reaching $1.6 \%$ at day 6 . A low level of radioactivity was also found in the bone marrow, only $2.5 \%$ at $1 \mathrm{~h}$, after ${ }^{59} \mathrm{Fe}-\mathrm{PVS}$ injection. The value did not show any marked change by day 6 . The radioactivity of the blood plasma was less than $1 \%$ throughout the examination.

Nonparenchymal and parenchymal liver cells obtained from ${ }^{59} \mathrm{Fe}-\mathrm{PVS}$ injected animals were isolated in order to determine the ${ }^{59} \mathrm{Fe}$-ferritin content at 3 and 4 days after injection. The ${ }^{59} \mathrm{Fe}$-ferritin content in the nonparenchymal cell fractions obtained 3 days after administration of ${ }^{59} \mathrm{Fe}$-PVS was about 2 times as high as that of the parenchymal cells. However, 4 days after the injection, the ferritin level in the nonparenchymal cells decreased to a level less than that of the parenchymal cells whose ferritin level remained relatively unchanged (Fig. 14). This phenomenon suggests the rapid mobilization of ferritin iron from the Kupffer cells.

\section{DISCUSSION}

The present study on anemic rats injected with ${ }^{59} \mathrm{Fe}-\mathrm{PVS}$ clearly demonstrates the important role of the liver in iron utilization for erythrocyte maturation. Nearly $60 \%$ of intravenously injected ${ }^{59} \mathrm{Fe}$ was found in the liver $6-24 \mathrm{~h}$ after injection and 
10 to $33 \%$ was found in the RBC, while spleen and bone marrow took up only $6.5 \%$ and $2.5 \%$ during the same period, respectively. The ${ }^{59} \mathrm{Fe}$ in the liver decreased gradually with a rapid increase in the radioactivity occurring in the RBC; no increase was observed in either the spleen or the bone marrow. The sum of radioactivity in the liver and RBCs was more than $90 \%$ at all times examined, which suggests that the liver is the main provision site of iron to precursors of the RBCs.

The immunohistochemical study revealed rapid and effective ferritin synthesis in Kupffer cells with ingested Fe-PVS. Ferritin appeared in the cytoplasm of the Kupffer cell as early as $5 \mathrm{~h}$ after Fe-PVS injection and the reaction intensity increased markedly 3 days after injection. In particular, a heavy deposition of ferritin was observed in the Kupffer cells located in the peripheral area of acini or "Zone 1 of Rappaport (25)". Four to six days after Fe-PVS injection, ferritin appeared in the parenchymal cells, mainly in the central area of acini or "Zone 3 " with a decrease in the amount found in the Kupffer cells. In the samples taken between 3 and 4 days after Fe-PVS injection, ferritin was found in Disse's spaces and sinusoids. This indicates the release of ferritin from the Kupffer cells into Disse's spaces and the sinusoids. The majority of the ferritin will be taken up by parenchymal cells and erythroid precursor cells as it moves slowly through the central vein of the sinusoidal blood stream. Therefore, only a small amount of ferritin will reach the general circulation.

It is reasonable to suppose that ferritin molecules can be released from Kupffer cells into Disse's spaces and sinusoids, since Kupffer cells are not fixed on the endothelial cells but move around on the porous endothelial layer; moreover, some of them directly face Disse's spaces (9). Many investigators have reported that a certain amount of iron is released from iron-loaded macrophages in the form of ferritin in vitro $(4,5,8,24,27)$. Parenchymal cells and precursors of RBCs found in the liver of anemic animals could take up these ferritin molecules by the specific receptor on the surface $(13,14)$. It was found in this study that the liver of the anemic rats contained some erythropoietic focuses.

It has now been widely accepted that reticulocytes contain a transferrin receptor on their surface $(3,10,12)$, and that transferrin serves as an iron supplier to reticulocytes for hemoglobin synthesis $(1,17)$. Yet, there is also some evidence to show that ferritin binds to the reticulocyte membrane by specific receptors in vitro, then the ferritin is internalized into the cells $(2,23,28)$. Simon et al. $(28)$ also showed that more than one half of the iron component of ${ }^{59} \mathrm{Fe}$-ferritin injected into normal and iron-defficient guinea pigs was taken up by the circulating reticulocytes and incorporated into the haem molecules. Therefore, there is a strong possibility that the ferritin released from the Kupffer cells is mainly taken up by the reticulocytes moving to the liver sinusoids.

Thus, the present experiments indicate that liver Kupffer cells will play a major role in iron metabolism in the processing iron compounds introduced into circulating blood and in iron transfer to precursors of RBCs or reticulocytes for their hemoglobin synthesis.

Acknowledgments. We thank Dr. H. Shigei of the board of the Shigei Medical Research Institute for his aid that made this study possible. We also thank Prof. M. Awai, Okayama University Medical School, Dr. M. Mori and Dr. N. Ishii for their helpful advice. 


\section{REFERENCES}

1. AISEN, P. The transferrins. in Iron in Biochemistry and Medicine, II, ed. Jacobs, A. and M. Worwood, Academic Press, London, pp. 87-129, 1980

2. Blight, G.D. and E.H. Morgan. Ferritin and iron uptake by reticulocytes. Br. J. Haematol. 55, 59-71, 1983

3. VAN BockXmeer, F.M. and E.H. Morgan. Transferrin receptors during rabbit reticulocyte maturation. Biochim. Biophys. Acta 584, 76-83, 1979

4. Brock, J.H., I. Esparza and A.C. LogIE. The nature of iron released by resident and stimulated mouse peritoneal macrophages. Biochim. Biophys. Acta 797, 105-111, 1984

5. Custer, G., S. Balcerzak and J. Rinehart. Human macrophage hemoglobin-iron metabolism in vitro. Am. J. Hematol. 13, 23-26, 1982

6. DeIss, A. Iron metabolism in reticuloendothelial cells. Semin. Hematol. 20, 81-90, 1983

7. Doolittle, R.L. and G.W. RichteR. Isolation and culture of Kupffer cells and hepatocytes from single rat livers, with observations on iron-loaded Kupffer cells. Lab. Invest. 45, 558-566, 1981

8. EsPARZA, I. and J.H. BROCK. Release of iron by resident and stimulated mouse peritoneal macrophages following ingestion of transferrin-antitransferrin immue complexes. $B r . \quad J$. Haematol. 49, 603-614, 1981

9. Fawcett, D.W. Bloom and Fawcett A Textbook of Histology, 11th ed., W.B. Saunders Company, Philadelphia, pp. 679-715, 1986

10. IACOPETta, B.J., E.H. MoRgan and G.C.T. YeOH. Transferrin receptors and iron uptake during erythroid cell development. Biochim. Biophys. Acta 687, 204-210, 1982

11. JACOBS, A. Ferritin: an interim review. Current Topics Hematol. 5, 25-62, 1985

12. JANDL, J.L. and J.H. KATZ. The plasma to cell cycle of transferrin. J. Clin. Invest. 42, 314-326, 1963.

13. Mack, U., L.W. Powell and J.W. Halliday. Detection and isolation of a hepatic membrane receptor for ferritin. J. Biol. Chem. 258, 4672-4675, 1983

14. Mack, U., E.L. Storey, L.W. Powell and J.W. Halliday. Characterization of the binding of ferritin to rat hepatic ferritin receptor. in Proteins of Iron Storage and Transport, ed. Spik, G., J. Montreuil, R.R. Crichton and J. Mazurier, Elsevier Sci. Pub., Amsterdam, pp. 203-206, 1985

15. Matsuno, T., M. Mori and M. Awai. Distribution of ferritin and hemosiderin in the liver, spleen, and bone marrow of normal, phlebotomized and iron overloaded rats. Acta Med. Okayama 39, 347-360, 1985

16. MiYazaki, M., S. WAhid, K. MiYano and J. Sato. Isolation and primary culture of adult rat liver cells. Tissue Culture 9, 187-190, 1983 (in Japanese).

17. Morgan, E.H. and E. BAKer. Iron uptake and metabolism by hepatocytes. Federation Proc. 45, 2810-2816, 1986

18. Muir, A.R. and L. Golberg. Observations on subcutaneous macrophages. Phagocytosis of irondextran and ferritin synthesis. Q. J. Exp. Physiol. 46, 289-298, 1961

19. Munro, H.N. and M.C. Linder. Ferritin; structure, biosynthesis, and role in iron metabolism. Phys. Rev. 58, 317-396, 1978

20. Ono, T., T. TsujII and S. Seno. A morphological study of ferritin synthesis in macrophages with ingested ferric hydroxide-potassium polyvinyl sulfate complexes. Cell Struct. Funct. 8, 267-279, 1983

21. Ono, T. and M. AwaI. Endocytic mechanism of macrophages to anionic foreign substances. $A c$ ta Histochem. Cytochem. 17, 547-563, 1984

22. ONO, T. and S. SENo. Endocytosis of cationic and anionic iron colloid particles by rat macrophages. Acta Histochem. Cytochem. 19, 105-118, 1986

23. Pollack, S. and T. Campana. Immature red cells have ferritin receptors. Biochim. Biophys. Res. Commun. 100, 1667-1672, 1981

24. Rama, R., J. SANChEz and J.-N. Octave. Iron mobilization from cultured rat bone marrow macrophages. Biochim. Biophys. Acta 968, 51-58, 1988

25. Rapparport, A.W., Z.J. Borowy, W.N. LongheEd and W.N. LotTo. Subdivision of hexagonal liver lobules into a structural and functional unit. Anat. Rec. 119, 11-33, 1954

26. Richter, G.W. The iron-loaded cell; the cytopathology of iron storage. Am. J. Pathol. 91, 363405, 1978 
27. Saito, K., T. Nishisato, J.A. Grasso and P. Aisen. Interaction of transferrin with iron-loaded rat peritoneal macrophages. Br. J. Haematol. 62, 275-286, 1986

28. Simon, M., P. MacPhail, T. Bothwell, G. Lyons, R. Baynes and J. Torrance. The fate of intravenously administered hepatic ferritin in normal, phenylhydradine-treated and scorbutic guneapigs. Br. J. Haematol. 65, 239-243, 1987

29. Sternberger, L.A., P.H. Hardy, J.J. Cuculis and M.G. Meyer. The unlabelled antibody enzyme method of immunohistochemistry. Preparation and properties of soluble antigen-antibody complex (horse radish peroxidase anti-peroxidase) and its use in identification of spirochetes. $J$. Histochem. Cytochem. 18, 315-333, 1970

30. Zamboni, L. and C. de Martino. Buffered picric acid-formaldehyde; A new, rapid fixative for electron microscopy. J. Cell Biol. 35, 148A, 1967 (Abstr).

(Received for publication, October 14, 1988) 